\title{
A abordagem de aspectos jurídicos na Audiência Pública da Saúde do Supremo Tribunal Federal
}

\section{Legal approaches in the Public Hearing on Health Issues of Supreme Court in Brazil (2010)}

\section{Alethele de Oliveira Santos}

Advogada, Especialista em Direito Sanitário e Mestre em Saúde Coletiva. Assessora Técnica do Conselho Nacional de Secretários de Saúde. Brasília, Brasil.

\section{Silvia Badim Marques}

Advogada, Especialista em Direito Sanitário e Doutora em Saúde Pública. Professora Assistente da Universidade de Brasília. Brasília, Brasil.

Resumo: Objetivos: O grande número de ações judiciais contra entes estatais pleiteando prestações de saúde levou o Supremo Tribunal Federal do Brasil a convocar uma audiência pública para discutir o problema, realizada em abril e maio de 2010. O estudo objetivou identificar os principais argumentos jurídicos contidos nos discursos proferidos na audiência. Metodologia: Análise do Discurso do Sujeito Coletivo (Lefèvre \& Lefrève, 2003), com utilização do software Qualiquantisoft. Resultados: 64 discursos analisados; 13 ideias centrais caracterizadas; identificadas abordagens jurídicas em $89 \%$ dos discursos; predominância do debate sobre a natureza do direito à saúde $(20,7 \%$ dos discursos), de abordagens sobre o fenômeno da judicialização $(14,6 \%)$ e sobre a decretação de repercussão geral e a proposta de súmula vinculante (10,4\%). Discussão: Os discursos ficaram adstritos pelas ideias de que o direito à saúde é direito subjetivo público passível de garantia pela via judicial e que a escassez de recursos obriga o administrador a fazer escolhas; que a discussão dos problemas sociais se deslocou para o Judiciário, tanto no Brasil como em outros lugares do mundo; que, no Brasil, o problema não é o Judiciário determinar cumprimento ao Executivo e sim o Executivo dar cumprimento ao que já está legalmente determinado; que não há invasão de poderes nas decisões judiciais e sim controle das omissões daqueles que são responsáveis pela implementação das políticas públicas. Conclusões: o direito à saúde merece observação e análise, não mais de seu contexto teórico, mas de seu contexto prático e diuturno nos tribunais e na Administração Pública.

Palavras chaves: Judicialização; políticas de saúde; Supremo Tribunal Federal (Brasil)

Resumen: Objetivos: El gran número de demandas contra entidades del Estado solicitando beneficios de salud llevaron a la Corte Suprema Federal de Brasil a convocar una audiencia pública para discutir el tema, celebrada en abril y mayo de 2010. El estudio tuvo como objetivo identificar los principales argumentos jurídicos contenidos en los discursos pronunciados durante la audiencia. Metodología: Análisis de Discurso del Sujeto Colectivo, desarrollado por Lefèvre y Lefèvre (2003), utilizando el software Qualiquantisoft. Resultados: 64 discursos analizados; 13 ideas centrales caracterizadas; enfoques legales identificados en el $89 \%$ de los discursos; prevalencia del debate sobre la naturaleza del derecho a la salud $(20,7 \%$ de las intervenciones), abordajes del fenómeno de la legalización (14,6\%) y la promulgación de alcance general y súmula vinculante (10,4\%). Discusión: Al opinar sobre la

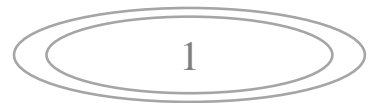


justiciabilidad, los discursos quedaron se astringidos a las ideas que el derecho a la salud es derecho subjetivo susceptible de ser garantizado a través de los tribunales y que la escasez de recursos requiere que el administrador haga elecciones para tomar decisiones; la discusión de temas sociales pasó al Poder Judicial, tanto en Brasil como en otros lugares del mundo; que, en Brasil, el problema no es el Poder Judicial determinar el cumplimiento al Ejecutivo, pero el Ejecutivo cumplir con lo que ya está determinado legalmente; que no hay invasión de competencias en las decisiones judiciales, pero el control de las omisiones de los que son responsables de la implementación de la política pública. Conclusiones: el derecho a la salud todavía sufre de observación y análisis, no su contexto teórico, sino en su contexto práctico y rutinario en los tribunales y en la Administración Pública.

Palabras clave: Judicialización; políticas de salud; Tribunal Supremo Federal (Brasil)

\begin{abstract}
Objectives: Large number of lawsuits against state entities claiming health benefits led the Supreme Federal Court of Brazil to convene a public hearing to discuss the issue, held in April and May 2010. The study aimed to identify the main legal arguments contained in the speeches given at the hearing. Methodology: Analysis of Collective Subject Discourse, developed by Lefèvre \& Lefevre (2003), using the software Qualiquantisoft. Results: 64 speeches analyzed; 13 central ideas characterized; legal approaches identified in $89 \%$ of speeches; prevalence of debate about the nature of the right to health (20.7\% of speeches), approaches to the phenomenon of legalization (14.6\%) and the enactment of general effect and the proposed binding precedent (10.4\%). Discussion: When opine on justiciability, the speeches were assigned by the ideas that the right to health is subjective right liable to guarantee public through the courts and that the scarcity of resources requires the administrator to make choices; the discussion of social issues shifted to the judiciary, both in Brazil and elsewhere in the world; that in Brazil, the problem is not the judiciary to determine compliance to the Executive, but the Executive to comply with what is already legally determined; that there is no invasion of powers in judicial decisions, but control of the omissions of those who are responsible for the implementation of public policy. Conclusions: the right to health still suffers from observation and analysis, not in its theoretical context, but in its practical context in the courts and in Public Administration.
\end{abstract}

Keywords: Law decisions; health policies; Federal Supreme Court (Brazil)

\title{
1 Introdução
}

O grande e crescente número de petições judiciais com pleitos referentes à aplicação do direito à saúde, como o fornecimento de medicamentos, leitos para internação, insumos e correlatos, assim como a reação dos gestores do sistema de saúde, réus dessas ações, fez com que a mais alta Corte do país se mobilizasse para angariar fundamentos técnicos para a tomada de decisões nessa matéria.

Para isso, o Supremo Tribunal Federal (STF) convocou audiência pública, com o objetivo de ouvir os especialistas, gestores públicos e profissionais envolvidos com a temática, em busca de mais subsídios técnicos e conhecimento sobre a matéria que 
permitissem maior racionalidade decisória para julgar ações que versam sobre saúde. Essa audiência - que ficou conhecida como a Audiência Pública da Saúde - foi convocada pelo Presidente do Supremo Tribunal Federal, Ministro Gilmar Mendes, e realizada nos dias 27, 28 e 29 de abril e 4, 6 e 7 de maio de 2010 (STF, 2009).

$O$ instituto da audiência pública é tido como adequado em regimes democráticos. Todavia, no caso brasileiro, os doutrinadores ainda não se debruçaram adequadamente sobre o tema (Machado e Dain, 2012). O posicionamento do STF, ao convocar audiências públicas, reflete sua convergência a uma corte inteiramente constitucional e a assunção das responsabilidades e ajustes sociais que tal postura requer.

\section{Objetivo e metodologia}

O estudo objetivou identificar os principais argumentos jurídicos contidos nos 64 discursos proferidos na Audiência, a partir da análise dos mesmos, disponíveis no sítio do STF (www.stf.jus.br).

Foram identificadas e analisadas as ideias centrais presentes nos discursos dos atores da referida audiência, focadas, exclusivamente, nos seus aspectos jurídicos.

As ideias centrais foram identificadas com o emprego da metodologia do Discurso do Sujeito Coletivo e são, como salientam Lefèvre e Lefèvre, uma descrição sintética dos argumentos encontrados em determinado discurso. Segundo esses autores, a ideia central tem a importante função de individualizar, dentro de um dado discurso, "suas especificidades semânticas, o que permite distingui-lo de outros discursos portadores de outras especificidades semânticas" (Lefèvre e Lefèvre, 2003, p. 25).

Foram lidos todos os discursos proferidos na referida audiência e identificadas as suas expressões-chave que são trechos literais das falas dos atores que sintetizam seus argumentos (Lefèvre e Lefèvre, 2003). Posteriormente, foram agrupadas as expressões-chave homogêneas, que são aquelas que possuem o mesmo núcleo de sentido, e, a partir desse agrupamento, foram identificadas ideias centrais relativas a cada grupo de expressões-chave. Para tanto utilizou-se o software de apoio à Metodologia do Discurso do Sujeito Coletivo, denominado Qualiquantisoft.

O uso dessa metodologia também permitiu identificar o quantum uma determinada ideia central esteve presente no total dos discursos. 


\section{Resultados}

As ideias encontradas referem-se a diversas teses sobre a garantia do direito social à saúde. Coube ao STF, tanto no apanhado dos dados apresentados na Audiência Pública, quanto na decisão exarada após a audiência, o sopesamento das mesmas para a análise de suas convergências e divergências.

Analisados os 64 discursos, foram identificadas 13 ideias centrais (Tabela).

Tabela. Ideias centrais dos discursos proferidos na Audiência Pública da Saúde.

\begin{tabular}{l|r}
\hline \multicolumn{1}{c|}{ Ideia central } & \multicolumn{1}{c}{$\%$} \\
\hline A - O direito à saúde deve ser garantido mediante políticas públicas. & 12,8 \\
B - O direito à saúde é garantia constitucional que independe de política & 7,9 \\
pública. & 14,6 \\
C - Abordagens sobre o fenômeno da judicialização. & 7,9 \\
D - Abordagens sobre o financiamento da política de saúde. & 6,7 \\
E - Conflitos existentes entre o direito individual e o direito coletivo. & 10,4 \\
F - Abordagens referentes à decretação de repercussão geral, relevância da \\
Audiência Pública e proposta de súmula vinculante. & \\
G - Há fraudes nos processos judiciais referentes à saúde, bem como na & 5,5 \\
Administração Pública. & 1,8 \\
H - Há solidariedade entre os entes federativos para a garantia do direito à & \\
saúde. & 4,3 \\
I - A responsabilidade deve ser atribuída a cada ente federativo, conforme as & \\
competências definidas na lei. & 6,7 \\
J - Há falhas na política pública de saúde. & 7,3 \\
K - Abordagens conceituais sobre a política de saúde. & 1,8 \\
L - O direito à saúde deve ser garantido mediante políticas públicas, todavia, \\
admitidas excepcionalidades. \\
M - Podem litigar em juízo por direito à saúde, somente os hipossuficientes. \\
N - Discursos sem temas de abordagem jurídica. & 1,2 \\
\hline
\end{tabular}

Fonte: STF (www.stf.jus.br). Elaborado pelas autoras.

A ideia central $A$ : "O direito à saúde deve ser garantido mediante políticas públicas" apareceu em $12,8 \%$ dos discursos analisados e abordou a concepção de que a garantia dos direitos sociais está intrinsecamente relacionada à elaboração e implementação de políticas públicas pelos entes federados brasileiros: União, Estados, Distrito Federal e Municípios.

Para os defensores da ideia $\mathrm{A}$, a integralidade a que se refere as disposições legais que garantem saúde não é um conceito aberto. Isso porque, além da 
necessidade de se alocar recursos escassos por meio de critérios distributivos, a evolução da medicina e o uso seguro de tecnologias médicas impõem um viés programático ao conceito de integralidade e ao próprio direito à saúde. Esse direito, para ser exercido sob a perspectiva da integralidade, depende, portanto, da existência de políticas públicas de saúde e das escolhas discricionárias do Estado Administrador, que elenca os fármacos, insumos e demais prestações de saúde que serão dispensados publicamente como parte do direito à saúde.

Essa ideia indicou, também, que o próprio STF já consolidou jurisprudência no sentido de que os três entes da federação são solidariamente responsáveis pelo cumprimento do mandamento constitucional de garantia da saúde (ver adiante, ideia $H)$.

Para a ideia A, a Portaria (GM) do Ministério da Saúde no 3916, de 1998, que aprovou a Política Nacional de Medicamentos (Brasil, 1998) e que tem como objetivo assegurar eficácia e qualidade dos medicamentos, promover seu uso racional e o acesso da população àqueles considerados essenciais, deve ser considerada parte integrante do direito à assistência farmacêutica.

Essa ideia considera que os protocolos clínicos e as diretrizes terapêuticas (PCDT) são códigos de conduta técnica, que sistematizam práticas sobre o uso de medicamentos para usuários do serviço de saúde e, por isso, devem ou deveriam ser reitores das possibilidades da oferta farmacêutica no âmbito do SUS e, com o mesmo efeito reagente, deveriam ser valorizados no âmbito de ações judiciais que demandam medicamentos em face do Estado.

Considera, também, que as dificuldades de atualização dos protocolos favorecem a ampliação de demandas perante o Poder Judiciário e que os PCDT são responsabilidade impostergável do Poder Público, que deve mantê-los atualizados e disponíveis para todos que acessam o SUS.

A ideia A reforça, também, a importância de se observar a Política Nacional de Assistência Farmacêutica no que ela é regulada pela Portaria (GM) do Ministério da Saúde $n^{\circ}$ 2.475, de 2006, que instituiu a Relação Nacional de Medicamentos Essenciais (RENAME) (Brasil, 2006), como parte integrante do direito à saúde. Isto porque tal política representa um instrumento norteador para a dispensação, no âmbito do SUS, de medicamentos de forma segura e eficaz. 
Essa ideia também indica que o SUS deve disponibilizar, de maneira geral, no mínimo, um representante de cada grupo farmacológico, com eficácia e segurança comprovadas.

Com esse fundamento, os defensores da ideia $A$ entendem que não há obrigação do Estado de disponibilizar medicamentos e tratamentos experimentais, não registrados na Agência Nacional de Vigilância Sanitária (ANVISA), ou não aconselhados pelos protocolos clínicos adotados pelo SUS e pela Política de Assistência Farmacêutica, porque as prestações públicas em saúde não podem ser expansíveis a ponto de deixar de observar as diretrizes legais vigentes. Foi ressaltado que medicamentos não registrados pelo órgão de vigilância sanitária representam risco para o paciente e espera-se que a sua concessão pelo Estado desapareça da jurisprudência brasileira.

Os argumentos que se enquadraram na ideia central A deixaram, por fim, as seguintes proposições ao STF: (i) que o acesso aos medicamentos na via judicial, como regra, se dê somente quando regularmente registrados na Anvisa ${ }^{1}$, nos termos do registro e em conformidade com as indicações dos protocolos e diretrizes clínicas e terapêuticas do Ministério da Saúde e listas oficiais do SUS; (ii) que o direito à saúde seja sempre exercido dentro dos moldes traçados pela política pública de saúde, destinada a atender a toda a coletividade, indistintamente.

Assim, para se conjugar o direito individual ao coletivo, essa ideia traz, como requisito fundamental, a observância das políticas públicas nas decisões judiciais sobre saúde.

Contrária a essa, a ideia central B: "O direito à saúde é garantia constitucional que independe de política pública" esteve presente em 7,9\% dos discursos proferidos na Audiência Pública da Saúde, tendo, por fundamento, a eficácia e aplicabilidade imediata do direito à saúde, de forma independente das políticas públicas estabelecidas. Contrapõe-se, portanto, aos fundamentos da ideia $A$.

De acordo com a ideia B, o Estado Democrático de Direito gravita em torno da dignidade da pessoa humana e, na ordem constitucional brasileira, os direitos

\footnotetext{
${ }^{1}$ Isto porque o fornecimento de medicamento sem registro contraria o artigo 12 da Lei $\mathrm{n}^{\circ}$ 6.360, de 1976 (Brasil, 1976), que determina que medicamentos sem registro no Ministério da Saúde não podem ser prescritos no território nacional fora do âmbito da pesquisa. A prescrição sem registro contraria também o Código de Ética Médica, instituído pela Resolução no 1.246, de 1988, do Conselho Federal de Medicina (CFM, 2009), que prevê, especialmente em seu artigo 124, que é vedado ao médico usar experimentalmente qualquer tipo de terapêutica ainda não liberada para uso no País fora do âmbito da pesquisa.
} 
fundamentais sociais são submetidos ao mesmo regime jurídico das garantias fundamentais e dos direitos individuais disciplinados nos Capítulos I, II, III, IV e V do Título II da Constituição Federal (Brasil, 1988). Para os atores que sustentam essa ideia, o artigo 196 da CF gera o dever do Estado de garantir integralmente o direito à saúde a seus cidadãos, com acesso universal e igualitário às ações e serviços de saúde, neles incluída a assistência farmacêutica.

A partir de tal premissa, é inconcebível a recusa do fornecimento gratuito de medicamento a paciente em estado grave e sem condições financeiras de custear medicamentos necessários ao seu tratamento, sejam esses básicos, estratégicos ou especializados $^{2}$, pelo simples fato de não constarem expressamente em políticas públicas.

A ideia B defende que o Princípio da Dignidade da Pessoa Humana, acrescido dos objetivos da República Federativa do Brasil e que constituem o fundamento do Estado brasileiro, deve garantir a reprodução da vida humana de forma digna e progressiva.

Outro importante fator analisado pela ideia $B$ é que a jurisprudência brasileira vem se firmando no sentido de que a saúde é um direito ilimitado, que implica na obrigação do Poder Público de fornecer todo e qualquer medicamento que um cidadão venha a necessitar.

Nesse caso, a responsabilidade pelo custeio dessas medidas é solidária entre todos os entes federados, ou seja, as prestações de saúde, nelas incluídas a assistência farmacêutica, são de responsabilidade comum da União, dos estados, do Distrito Federal e dos municípios. Uma vez acionado em juízo qualquer um desses entes, ele deve arcar com a responsabilidade do fornecimento da prestação sanitária,

\footnotetext{
${ }^{2}$ A Política Nacional de Medicamentos contempla medicamentos de três componentes: básicos, estratégicos e especializados, sendo que cada qual segue uma diretriz política específica para seu financiamento e dispensação dentro do SUS. Os medicamentos básicos são aqueles inseridos na Assistência Farmacêutica na Atenção Básica, considerados essenciais, destinados a atender necessidades prioritárias de saúde da população e constantes da Relação Nacional de Medicamentos Essenciais, a ser periodicamente revista pela Comissão Técnica e Multidisciplinar de Atualização da Rename (COMARE), conforme previsto na Portaria do Ministério da Saúde no 3916 de 1998 (Brasil, 1998). Os medicamentos estratégicos são aqueles "utilizados em doenças que configuram problemas de saúde pública, que atingem ou põem em risco as coletividades e cuja estratégia de controle concentra-se no tratamento de seus portadores" (Conass, 2007, p. 64). Os medicamentos de componente especializado são aqueles "destinados ao tratamento de patologias específicas que atingem um número limitado de usuários, os quais, na maioria das vezes, utilizam-nos por períodos prolongados. Entre os usuários desses medicamentos estão: transplantados, doentes de insuficiência renal crônica, esclerose múltipla, hepatite viral crônica B e C, epilepsia e esquizofrenia refratária, doenças genéticas como fibrose cística, doença de Gaucher, entre muitos outros" (Conass, 2007, p. 90). São esses medicamentos cuja dispensação está prevista nos protocolos clínicos e diretrizes terapêuticas adotados no SUS.
} 
independente da existência de qualquer pacto infraconstitucional em sentido contrário entre os entes federados.

Traz ainda o argumento de que, mesmo com imperfeições, a participação da magistratura tem se relevado de extrema importância para a melhoria da assistência farmacêutica no Brasil, e que as decisões judiciais acabam por gerar um "efeito pedagógico" perante o Poder Executivo, que se vê compelido a melhorar os serviços de saúde para atender os cidadãos de forma integral, revendo a política e a estrutura organizacional do SUS.

A ideia central C: "Abordagens sobre o fenômeno da judicialização" foi o tema que ocupou, percentualmente, a maior parte dos discursos da Audiência Pública da Saúde no STF, estando presente em $14,6 \%$ deles, refletindo o fato de, na última década, muito se ter escrito sobre a eficácia e a judicialização dos Direitos Fundamentais Sociais.

Para os apoiadores da ideia C, a Constituição Federal assegura ao cidadão o direito à saúde e o direito ao acesso à Justiça. Portanto, há uma busca por conciliação entre a dimensão subjetiva, quer individual ou coletiva do direito à saúde e a dimensão objetiva da saúde como dever da sociedade e do Estado. A judicialização deve ser sensível a ambas as dimensões.

O reconhecimento da complexidade da garantia do direito à saúde deixa para trás o momento de euforia, representado por teses revolucionárias, que tinham o Poder Judiciário como salvador do Estado Social, assim como relativiza a doutrina conservadora que, por muito, disciplinou a existência da programaticidade dos Direitos Fundamentais Sociais, devido à total ausência de imperatividade normativa e sua impraticabilidade.

A evolução do discurso sobre a eficácia dos Direitos Sociais e a função do Poder Judiciário na sua implementação está no momento de definição quanto a sua amplitude. Sabemos, contudo, que as portas de abertura para os casos individuais não podem ser fechadas, ainda que se tenha de trabalhar de uma forma mais proativa na coordenação geral do sistema e na minimização da judicialização de suas políticas.

A ideia $C$ expressa o entendimento do que vem sendo denominado de "Judicialização da Saúde Brasileira", termo polissêmico (Carvalho, 2004) cuja principal acepção refere-se ao crescimento do número de demandas judiciais individuais e não a intervenções indevidas de um poder sobre outro. 
A judicialização no Brasil decorreria do modelo constitucional brasileiro e, portanto, em alguma medida, ela é inevitável. Tem faceta negativa, pois, na medida em que uma matéria precisa ser resolvida mediante uma demanda judicial, é sinal de que ela não pôde ser atendida administrativamente. A faceta positiva decorre de que, quando um direito fundamental não está sendo observado, é fundamental que se possa recorrer ao Poder Judiciário para garantir sua tutela.

Assim, por um lado, a atuação do Poder Judiciário é fundamental para o exercício efetivo da cidadania e para a concretude do direito social à saúde e, por outro, as decisões judiciais têm significado um forte ponto de tensão perante os elaboradores e executores das políticas públicas voltadas para atender esse direito de forma coletiva.

Os partidários da ideia $C$ defendem que é preciso estabelecer parâmetros para que a atuação do Judiciário possa se pautar por critérios de racionalidade, eficiência, e, pela superação da falta de critérios universais que tem tornado, no âmbito dos Estados, o sistema extremamente disfuncional e desigual, e propõem a alternativa da parceria institucional: câmaras prévias de conciliação compostas pelas instituições envolvidas, previamente reunidas para encontrar solução para casos concretos. Entendem, ainda, ser preciso refletir sobre a normatização e a definição de marcos legais mais precisos para as políticas públicas de saúde.

Entendem, por fim, que não existem fórmulas miríficas; reconhecem que é preciso resguardar a situação e a natureza da função jurisdicional e defendem que a decisão judicial deve levar em conta razões técnicas, médicas e econômicas, sem o que, esse processo geraria insegurança jurídica.

Outra abordagem encontrada nos discursos proferidos na Audiência Pública da Saúde no STF diz do financiamento da política de saúde. A ideia central D: "Abordagens sobre o financiamento da Política de Saúde" pautou 7,9\% dos discursos proferidos naquela ocasião.

A ideia D ocupa-se do fato de que o financiamento do SUS depende de recursos do Orçamento da Seguridade Social da União, dos Estados, do Distrito Federal e dos Municípios, além de outras fontes, e que o direito à saúde deve conterse dentro dos limites orçamentários.

Nesse sentido, existem defensores do argumento de que as determinações judiciais devem ser encaminhadas tanto para os secretários de saúde como para os secretários de fazenda. Isto porque as demandas judiciais extrapolam o orçamento 
destinado ao setor saúde e não há um fundo para atender as eventuais demandas judiciais.

Esse argumento considera que existe uma questão central a ser enfrentada no processo de judicialização: o Princípio da Reserva do Possível.

Segundo Barcellos:

a expressão reserva do possível procura identificar o fenômeno econômico da limitação dos recursos disponíveis diante das necessidades quase sempre infinitas a serem por eles supridas. No que importa ao estudo aqui empreendido, a reserva do possível significa que, além das discussões jurídicas sobre o que se pode exigir judicialmente do Estado - e, em última análise, da sociedade, já que é esta que o sustenta - é importante lembrar que há um limite de possibilidades materiais para esses direitos (Barcellos, 2002, p. 260).

A consequência da alocação de recursos para o cumprimento das ordens judiciais é o comprometimento do orçamento destinado às políticas de saúde programadas, com prejuízo para um número significativamente maior de pessoas que dependem dos programas do SUS.

Portanto, no entendimento dos defensores da ideia D, a atuação do administrador está limitada pela cláusula de reserva do financeiramente possível, que é um dos fundamentos maiores da defesa da União junto às liminares que são concedidas para bloqueio de bens ou fornecimento de determinados medicamentos e de serviços de saúde.

Para tanto, defendem esses atores que é preciso que se discuta, no âmbito da judicialização, a questão do orçamento da saúde, pois a simples ausência de previsão orçamentária não pode impedir a atuação do Poder Judiciário frente à garantia do direito à saúde. É preciso que existam dados concretos e, também, é preciso que se discuta, na seara política, o orçamento e o financiamento do setor. De toda forma, importa discutir a aprovação de lei complementar que regulamentará a Emenda Constitucional ํㅡㄹ 29, de 2000, de forma a garantir o financiamento do setor, inclusive com maior repasse de recursos a estados e municípios, e para minimizar o impacto do subfinanciamento. ${ }^{3}$

A próxima ideia central identificada $\mathrm{E}$ : "Conflitos existentes entre o direito individual e o direito coletivo" ocupou 6,7\% dos argumentos expostos nos 64 discursos da Audiência Pública da Saúde no STF.

\footnotetext{
${ }^{3}$ À data de realização da audiência, a referida lei-complementar ainda não tinha sido aprovada pelo Congresso Nacional.
} 
Essa ideia sustenta que o Poder Judiciário tem sido receptivo à grande maioria das ações judiciais individuais interpostas, mas tem se mostrado bastante refratário às demandas coletivas. Ressalta que a atuação do Judiciário nas ações individuais de saúde tem repercussão direta sobre a alocação de recursos públicos, atingindo, ainda que não intencionalmente, toda a população beneficiada pelo SUS e, portanto, o direito à saúde sob a perspectiva coletiva.

Nessa inevitável colisão de direitos, deveria prevalecer a saúde coletivamente considerada e a garantia de implementação de políticas públicas voltadas ao atendimento das principais demandas de saúde de toda a população brasileira.

O papel do Judiciário, portanto, para esses atores, não deve ater-se à postulação individual, mas extrapolar os limites do processo individual e alcançar a programação política, controlando a elaboração e oferta coletiva de políticas públicas e prestações sanitárias para todos que delas necessitem.

Quando não houver política pública, o Judiciário deve ser responsável por deflagrar um diálogo institucional e compelir a autoridade pública a ter alguma política articulada em relação àquela demanda. A valorização da tutela coletiva é entendida como importante iniciativa, na medida em que visa resolver o problema de forma coletiva e não restrita a casos individuais.

Concluiu a ideia $E$ que defender a saúde é defender a própria existência de vida digna na sociedade brasileira, buscando, em primeiro lugar, o atendimento coletivo, mas sem desproteger o indivíduo no objeto da tutela judicial.

A ideia central F: "Abordagens referentes à decretação de repercussão geral, relevância da Audiência Pública e proposta de Súmula Vinculante" trouxe argumentos técnicos acerca dos instrumentos utilizados pela Corte Superior e sua aplicação ao direito à saúde, e ocupou $10,37 \%$ dos discursos proferidos.

A convocação da Audiência Pública da Saúde foi motivada por pedidos de suspensão de segurança, suspensão de liminar e suspensão de tutela antecipada, de competência da Presidência do STF. Teve por objetivo esclarecer as questões técnicas, científicas, administrativas, políticas e econômicas envolvidas nas decisões judiciais sobre saúde e analisar as consequências da atuação do Poder Judiciário para a ordem, a saúde e a economia públicas ${ }^{4}$.

\footnotetext{
4 A Audiência Pública da Saúde foi realizada após a vigência da Emenda Regimental $n^{\circ} 29$ que passou a prever as competências e o procedimento de convocação e realização de audiências públicas no âmbito do STF, com fundamento no previsto na Lei $n^{\circ} 9.868$, de 1999 , e, depois, referida também na Lei no 9.882, de 1999, e artigo 13, inciso XVII, do Regimento Interno daquela Corte.
} 
Os autores dos discursos que contém a ideia $F$ consideram que a participação de diferentes grupos sociais em processos judiciais de grande significado para toda a sociedade cumpre uma função de integração social extremamente relevante no Estado de Direito. E que, consequentemente, o STF poderá contar com os benefícios decorrentes dos subsídios técnicos, políticos, jurídicos e acadêmicos aportados por eles para resolver os conflitos complexos que envolvem o direito à saúde.

Consideram, ainda, que, para o STF, a convocação da audiência, além de contribuir para a qualidade da prestação jurisdicional, garante novas possibilidades de legitimação dos julgamentos do Tribunal no âmbito de sua tarefa precípua de guarda da Constituição e, também, no exercício de sua competência de proteção do interesse público e da segurança jurídica.

Os atores que abordaram esses temas (ideia F) trouxeram ao debate a informação de que tramita na Corte proposta de súmula vinculante e um recurso extraordinário, com repercussão geral reconhecida, que envolvem questões relativas à eficácia do artigo 196 da Constituição.

A Proposta de Súmula Vinculante $n^{\circ} 4$ visa tornar expresso os seguintes entendimentos em relação às demandas judiciais de saúde: "a responsabilidade solidária dos entes da federação no que concerne ao fornecimento de medicamentos e tratamentos" e "a possibilidade de bloqueio de valores públicos para o fornecimento de medicamento e tratamento".

Esses atores trouxeram também para o debate entendimentos segundo os quais decisão judicial que determine o bloqueio de verbas públicas para o cumprimento de tutela antecipada ou liminar além de violar preceitos da Constituição (art. 100, $\S \S 2^{\circ}$ e $3^{\circ}$; art. 167, inciso II), viola o direito à vida e à saúde dos usuários do SUS - e, portanto, o próprio artigo 196 e o princípio da proporcionalidade - diante da existência de outros meios coercitivos menos gravosos ao interesse público e constitui-se em dano no orçamento dos entes da Federação.

O Recurso Extraordinário $\mathrm{n}^{\circ}$ 566.471 - que tem repercussão geral reconhecida - questiona se situação individual pode, em razão do alto custo da prestação de saúde demandada, pôr em risco a assistência global à saúde do todo. Tratava-se, aqui, do direito ao fornecimento de medicamento de alto custo, imprescindível para o tratamento da hipertensão pulmonar que, até a data da propositura da ação, não era previsto na relação oficial de medicamentos dispensados pelo SUS. 
A ideia central G: "Há fraudes nos processos judiciais referentes à saúde, bem como, na Administração Pública" respondeu aos questionamentos do STF sobre esses fatos, em relação à dispensação de medicamentos e outras prestações públicas de saúde. Esteve presente em $5,5 \%$ do total de discursos.

Corroborando a ideia, foi feita a narrativa de um caso de fraude, indicado pela crescente demanda em busca dos medicamentos Infliximab, Efalizumab e Etanercept, prescritos como "última esperança" para os portadores de uma doença de pele incurável. Para o relator do fato, os prejuízos financeiros retornariam aos cofres públicos, todavia, os danos causados à saúde das pessoas, pelo consumo inadequado dos medicamentos, não poderiam ser financeiramente mensurados.

Ainda sobre fraudes, foi chamada a atenção para os casos em que os laboratórios produtores de medicamentos recrutam grupos de pacientes para pesquisas clínicas, a fim de testar a eficácia de novos produtos que pretendem lançar no mercado, e, ao encerrar o estágio da pesquisa, suspendem o seu fornecimento, o que leva os pacientes a demandarem esses novos medicamentos em juízo, pleiteando o fornecimento da droga pesquisada (e ainda não reconhecida) pelo Poder Público.

A ideia $G$ utilizou o argumento de que a judicialização beneficia os mais abastados e os mais espertos, gerando o efeito referido pela doutrina como Free Rider Effect (efeito carona).

A ideia $G$ inclui, também, a discussão das fraudes que ocorrem no sistema público de saúde e que, como condutas ilícitas devem ser apuradas caso a caso. Esses argumentos expõem a necessidade de constituir comissões técnicas no âmbito federal, estadual e municipal do SUS, com o fim de detectar irregularidades na dispensação de medicamentos e outras ações de trato com saúde pública, a exemplo de insumos, inclusive prótese e órtese, exames, tratamento etc.

Outra discussão travada durante a audiência cuidou da interpretação da responsabilidade dos entes federados na garantia do direito à saúde. A ideia central H: "Há solidariedade entre os entes federativos para a garantida do direito à saúde" correspondeu a $1,8 \%$ do total de discursos.

Os argumentos da ideia $\mathrm{H}$ afirmam que o Poder Judiciário, acompanhado pela doutrina majoritária, tem entendido que a competência comum dos entes resulta na sua responsabilidade solidária para responder pelas demandas de saúde e que não 
há dúvida de que cabe à União, aos estados, ao Distrito Federal e aos municípios agirem em conjunto no cumprimento do mandamento constitucional.

Em relação à solidariedade passiva, a jurisprudência dos tribunais especificamente a do STF - é firme no sentido de que ela existe. Isso decorre do próprio ordenamento jurídico, da nossa Constituição Federal, no artigo 198 e na forma de custeio do SUS.

Refletindo mais um antagonismo entre teses apresentadas, o fundamento expresso pela ideia central $\mathrm{H}$, foi controvertido pelo discurso atribuído à ideia central $\mathrm{I}$ : "A responsabilidade deve ser atribuída a cada ente federativo, conforme as competências definidas na lei". A ideia I participou de $4,3 \%$ dos discursos proferidos na audiência pública.

$\mathrm{Na}$ concepção da ideia I, a responsabilidade solidária não se presume, segundo a lição do Código Civil, mas decorre da lei ou do contrato. Portanto, não pode ser estabelecida por construção jurídica, quando a Constituição e as leis definiram a quem toca a responsabilidade no caso de atendimento à saúde. Apresenta por fundamentos: o Decreto Lei oㅡ 200, de 1967 (Brasil, 1967), e, principalmente, pela divisão de competências no âmbito do SUS, expressas no artigo 16 da Lei no 8.080, de 1990 (Brasil, 1990).

Segundo a ideia I, o entendimento pela responsabilidade solidária tem levado os magistrados à condenação indistinta e simultânea da União, dos estados e dos municípios na prestação jurisdicional reclamada pelo autor. Tal conduta tem contribuído para tumultuar o cumprimento da ordem ao invés de apressá-lo.

Para a ideia I, a responsabilidade solidária concebe-se no âmbito do SUS sobre o conjunto das ações, mas não em cada tipo de ação, nitidamente inserida na competência de cada ente político. A gestão da saúde pública pressupõe uma divisão interna de tarefas. Todavia, enquanto não for formulada a política, não existe a divisão de tarefas/competências, daí a responsabilidade é solidária. Esse entendimento, informam os defensores da ideia I, já foi acolhido pelo Supremo Tribunal Federal no Recurso Extraordinário 1895191/RS.

A ideia I propõe a definição dos sujeitos passivos nas demandas por prestações de saúde. Entende que a jurisprudência dominante que consagra uma solidariedade entre todos os entes federativos cria grande dificuldade administrativa e dispêndio de recursos, porque há três estruturas que passam a funcionar para, em juízo, atuarem para a defesa da Fazenda Pública. 
Deste modo, o correto, segundo a ideia I, seria que, observadas a responsabilidade do ente, a jurisprudência precisaria, em nome da racionalidade, da eficiência e da economia de recursos escassos, estabelecer que o réu da ação seja a entidade estatal responsável por aquela prestação e não outra.

Outra ideia central identificada, ideia J, estabelece que "há falhas na política pública de saúde", e apresentou reflexões importantes sobre a ausência de marcos legais no país e ser esse fato o mote desencadeador das demandas judiciais por saúde. Ela apareceu em 6,7\% dos discursos proferidos.

Para os atores que trouxeram a debate a ideia J, a Constituição Federal, no artigo 196, não afirma que os serviços de saúde devem ser gratuitos - como foi feito para o ensino obrigatório (artigo 208, parágrafo 1ํํ). No entanto, essa gratuidade resta evidente quando esse mesmo dispositivo estabelece que a saúde é um dever do Estado, sendo o financiamento público previsto por tributos e contribuições indicados.

Para eles, a Lei n 8.080, de 1990, no seu artigo 6º, I, "d", diz que a assistência terapêutica será integral, e (no artigo 43) que "a gratuidade das ações e serviços de saúde fica preservada nos serviços públicos e privados contratados, ressalvando-se as cláusulas dos contratos ou convênios estabelecidos com as entidades privadas" (Brasil, 1990).

Como contraponto, foi argumentado que, ao ser lido o artigo 200 da CF, percebe-se que não foi dada ao SUS qualquer competência normativa, competindoIhe, nesse campo, o poder de controlar, fiscalizar e participar da produção de medicamentos (inciso I). Corroborando esse entendimento, o artigo 197 da CF afirma, textualmente, que caberá ao poder público, dispor, nos termos da lei, sobre as ações e serviços de saúde, consideradas de relevância pública.

Sob esse prisma, a Lei nº 8.080, de 1990, previu o poder dos órgãos públicos que compõem o SUS de elaborarem normas com relação à produção de insumos e equipamentos, mas não traz expressa menção à palavra medicamentos (art. 16, X). Todavia, é dever questionar até que ponto as normas editadas pelo SUS (cuja direção, no âmbito da União, compete ao Ministério da Saúde) são vinculantes, considerando que a competência preponderante para editar normas é do Poder Legislativo.

Ou seja, não se nega a competência técnica dos órgãos do Ministério e outros para explicitarem conceitos jurídicos indeterminados contidos em lei, mas a impossibilidade de inovarem a ordem jurídica, estabelecendo limites, consequências 
e sanções. A partir desse diagnóstico, os que alegam que há falhas na política pública de saúde (ideia $\mathrm{J}$ ) entendem que a solução dessa questão está condicionada a uma regulação com base em marco legal preciso.

Para outros, no entanto, tirante a inflação normativa do poder regulador da Administração Pública e a pressão política sobre o Congresso para não regulamentar a Emenda Constitucional no 29, o Sistema de Saúde dispõe de uma excelente base normativa, tanto no plano constitucional como infraconstitucional, não podendo a regulação ser considerada falha.

E conclui que não há que se render às incapacidades gerenciais existentes no SUS e suas inadimplências orçamentárias. Ao contrário, o SUS deve ser compelido a superá-las.

Os argumentos da ideia central $\mathrm{J}$ indicaram, também, as falhas existentes no Poder Judiciário que, na contramão da superação dos problemas da política de saúde, exara decisões que atendem pedidos em aberto de medicamentos. Cada vez mais são comuns decisões lavradas da seguinte forma: "determina a entrega do medicamento " $x$ " e quaisquer outros que forem considerados necessários ao longo do tratamento". Com isso são criados títulos executivo-judiciais absolutamente abertos que geram execuções intermináveis em flagrante violação do Código de Processo Civil.

A ideia central K: "Abordagens conceituais sobre a política de saúde" elencou diretrizes, conjugação de esforços entre os entes federados e a responsabilidade sanitária, expressa constitucionalmente, para os municípios. As pautas conceituais ocuparam $7,3 \%$ do total de discursos.

No âmbito dessa discussão, alegou-se que, em simetria com as coordenadas constitucionais, o SUS foi organizado pela Lei no 8.080, de 1990, cuja elaboração esmerou na divisão de responsabilidade entre os entes, com a preocupação de evitar superposição de ações, em homenagem ao princípio da direção única, e, do mesmo modo, a duplicação de meios para a consecução da mesma finalidade. O processo de descentralização, no entanto, passou, inicialmente, por um processo de transição, que se iniciou com a extinção do Instituto Nacional de Assistência Médica da Previdência Social (INAMPS), com a sanção da Lei ํㅡ 8.689, de 1993, e com a transferência de seus encargos para estados e municípios. A União viu-se despojada de meios para a prestação de assistência médica diretamente a indivíduos, que 
passou à responsabilidade de estados e municípios, segundo o seu grau de complexidade.

Atualmente, as portarias do Ministério da Saúde, ao estabelecerem as políticas públicas de saúde, disciplinam qual o ente competente e qual a forma de financiamento das prestações de saúde de acordo com essa divisão de competências.

A ideia central L: "O direito à saúde deve ser garantido mediante políticas públicas, todavia admitidas excepcionalidades" ocupou $1,8 \%$ dos discursos e tratou dos casos em que houve o deferimento de medicamentos fora das listas oficiais do SUS ou sem registro na Anvisa.

Segundo os atores que trouxeram essa ideia ao debate, essa não deve se constituir em regra, mas em exceção; e nunca deve ocorrer em sede de antecipação de tutela ${ }^{5}$, mas somente em sentença prolatada após a necessária dilação probatória ${ }^{6}$.

A partir daí, o fundamento da garantia de tratamento diferenciado a um determinado indivíduo está na configuração de um critério de diferenciação deste com os demais indivíduos, por especificidades médicas que não são tratáveis dentro dos padrões coletivos.

Outro caso que há de constituir-se por exceção diz da obrigação do Estado de fornecer prestação de saúde prescrita por médico não pertencente aos quadros do SUS ou sem que o pedido tenha sido previamente feito à Administração Pública.

A necessidade de médico credenciado pelo SUS como agente da própria Administração pode - e deve - ser deferida como forma de melhor racionalização dos próprios recursos do SUS e ainda como forma de garantia de um atendimento universal. Porém, não se pode obstaculizar a prestação do direito à saúde quando o próprio Estado não dispuser de especialista no caso, seja em razão de localidade desprovida de desenvolvimento ou em área de saúde onde a iniciativa privada possua maiores recursos tecnológicos.

\footnotetext{
${ }^{5}$ Modalidade trazida pelo art. 273 do Código de Processo Civil que autoriza, nas hipóteses nele apontadas, a possibilidade de o juiz conceder ao autor ou ao réu, nas ações dúplices, um provimento liminar que, provisoriamente, lhe assegure o bem jurídico a que se refere a prestação de direito material reclamada como objeto da relação jurídica envolvida no litígio. Trata-se de direito subjetivo processual segundo o qual, dentro dos pressupostos rigidamente traçados pela lei, a parte tem o poder de exigir da Justiça, como parcela da tutela jurisdicional a que o Estado se obrigou.

${ }^{6}$ Prazo concedido igualmente ao autor e ao réu para a produção de provas ou a execução de diligências necessárias para comprovação dos fatos alegados.
} 
Os atores que discutiram a ideia $L$ mencionaram que o Judiciário normalmente concede as liminares sem ouvir a parte contrária, o que deveria ocorrer somente em sede de exceção. A solução, para eles atores, seria o equilíbrio.

A doutrina colocou esse equilíbrio numa expressão que já não é nova inclusive de uso do próprio Supremo - que é "decidir com base no mínimo existencial". Ou seja, quando o pedido da parte for imprescindível para a própria sobrevivência, realmente não haverá como o Judiciário negá-lo. O ponto-base do equilíbrio do mínimo existencial é que, embora haja priorização da política administrativa do SUS, o Judiciário não tem como deixar de garantir o direito à saúde, previsto na Constituição, em especial quando refletir no direito à vida.

Presente em 1,2\% do total de discursos, a ideia central M: "Podem litigar em juízo por direito à saúde, somente os hipossuficientes" pressupõe que, se a saúde pública é direito dos pobres, apenas pobres poderiam litigar em juízo.

Esses argumentos vieram enraizados no entendimento de que, em primeiro lugar, o juiz deve exigir a prova de que a parte não tenha efetivamente condição de adquirir aquele medicamento.

Sabendo-se que o Estado brasileiro não tem recursos suficientes para arcar com todos os medicamentos necessários para todos os cidadãos, há que se exigir prova da hipossuficiência do litigante. Nos casos em que ele puder pagar pelo medicamento terá que adquiri-lo por vias próprias, para que não se prejudique o direito coletivo, e se atendam as pessoas mais necessitadas com prioridade.

Por fim, $11,0 \%$ dos discursos não trouxeram abordagens jurídicas em seus conteúdos, detendo-se em aspectos político-administrativos e na narrativa de dilemas enfrentados na aplicação do direito à saúde.

\section{Discussão}

Em 17 de março de 2010, após a realização da Audiência Pública da Saúde e o sopesar das diferentes ideias sustentadas nessa audiência, o Plenário do Supremo Tribunal Federal decidiu os recursos: das Suspensões de Tutela (STA) 175, 211 e 278; das Suspensões de Segurança 3724, 2944, 2361, 3345 e 3355; e da Suspensão de Liminar (SL) 47, que diziam respeito ao fornecimento de medicamentos de alto custo ou tratamentos a pacientes de doenças graves que recorreram ao Poder Judiciário. $O$ voto expresso pelo relator foi seguido unanimemente pelos demais ministros (STF, 2010). 
Observe-se que o julgamento foi favorável aos pacientes (pólo ativo) dos processos judiciais em apreço. Todavia o STF foi cauteloso ao indicar que cada caso fosse avaliado com as suas especificidades e atendo-se aos elementos políticos que envolvem a oferta pública de medicamentos.

O voto do Ministro Gilmar Mendes, nos processos mencionados, foca-se nos seguintes pontos: (i) a exigência de suficiente produção de provas; (ii) que as provas tivessem cunho científico; (iii) demonstração de adequação da prestação de saúde ao que se pretende na ação judicial; (iv) a aferição acerca do registro do medicamento e das possibilidades de aquisição pelo Estado; (v) existência de evidências científicas e adequação aos protocolos clínicos e diretrizes terapêuticas adotados pelo SUS; (vi) aferição, se existente, de política pública que contemple o pretendido na ação judicial; (vii) aferição, se existente, de política de dispensação de medicamento sustentada pela medicina baseada em evidências; (viii) a admissão da medicina baseada em evidências de modo a permitir questionamento de ordem científica acerca da adequação da prestação de saúde pretendida; (ix) que a argumentação de que a reserva do possível (escassez de recursos) por si só não elimina a obrigação do Estado (União, estados, Distrito Federal e municípios) quanto ao fornecimento de prestações de saúde; $(x)$ a necessária apreciação dos argumentos de lesão à ordem, economia e separação de poderes; e, (xi) a solidariedade entre os entes da federação quanto à política pública de saúde.

O relator reconheceu no voto as limitações do Poder Judiciário face à complexidade do tema. Todavia, por não restar-Ihe alternativa que não decidir o caso concreto que the é submetido, o relator indicou pela necessidade de sopesamento dos argumentos de cada uma das teses, verificadas as especificidades de cada caso.

Comparadas as ideias centrais de abordagem jurídica com a decisão comentada é fácil perceber a incidência de algumas delas.

O STF mencionou, na decisão, a realização de Audiência Pública e a decretação de Repercussão Geral em Recurso Extraordinário. Esse tema ocupou $10,7 \%$ do total das ideias centrais (ideia $F$ - "Abordagens referentes à decretação de repercussão geral, relevância da Audiência Pública e proposta de súmula vinculante").

Sobre a solidariedade entre os entes, correspondente às ideias centrais H ("Há solidariedade entre os entes federativos para a garantia do direito à saúde") e I ("A responsabilidade deve ser atribuída a cada ente federativo, conforme as 
competências definidas na lei"), o STF considerou que os entes são solidários entre si e que o modelo de organização do sistema não altera essa solidariedade, alinhandose aos $1,8 \%$ dos depoentes da audiência.

As ideias centrais A ("O Direito à saúde deve ser garantido mediante políticas públicas") e $\mathrm{B}$ ("O Direito à saúde é garantia constitucional que independe de política pública") ocuparam $12,8 \%$ e $7,9 \%$, respectivamente, do total analisado. No entanto, a decisão do STF posicionou-se de forma a contemplar o exposto no Discurso Coletivo referente a ideia L: "O direito à saúde deve ser garantido mediante políticas públicas, todavia, admitidas excepcionalidades", que ocupou $1,8 \%$.

Ao manifestar-se sobre a judicialização, tema de $14,6 \%$ dos discursos e compreendido pela ideia central $\mathrm{C}$, o STF entendeu que o direito à saúde é direito subjetivo público passível de garantia pela via judicial e que a escassez de recursos obriga o administrador a fazer escolhas; que a discussão dos problemas sociais se deslocou para o Judiciário, tanto no Brasil como em outros lugares do mundo; que, no Brasil, o problema não é o Judiciário determinar cumprimento ao Executivo e sim o Executivo dar cumprimento ao que já está legalmente determinado; que não há invasão de poderes nas decisões judiciais e sim controle das omissões daqueles que são responsáveis pela implementação das políticas públicas.

Complementarmente, o STF admitiu a existência do conflito entre direito coletivo e direito individual, correspondente à ideia central E ("Conflitos existentes entre o direito individual e o direito coletivo") que esteve presente em $6,7 \%$ dos discursos.

Acerca do financiamento do setor (ideia central D), correspondente a 7,9\%, o STF entendeu especialmente que não há que se prender à cláusula de reserva do possível. Todavia é preciso atentar - vez que a atuação do Judiciário pode causar tensão entre os gestores que, compelidos a atender ordens judiciais, podem comprometer suas possibilidades financeiras e seus planejamentos - que é preciso entender a razoabilidade existente entre a possibilidade estatal de cumprir a pretensão e sua disponibilidade financeira.

Sobre a existência de fraudes (ideia central G), tema de 5,5\% do total de discursos, o STF afirmou que não há que ocorrer padronização de pedidos judiciais nem de decisões sob pena de não contemplar o caso concreto e de criar obstáculos à gestão. 
O STF não se manifestou sobre a ideia central M: "Podem litigar em juízo por direito à saúde somente os hipossuficientes".

\section{Conclusões}

Pelo que se expôs, não há dúvidas da importância da Audiência Pública da Saúde para o posicionamento dos atores envolvidos na judicialização das políticas de saúde face à Corte Constitucional do País e do STF, que obteve importantes subsídios técnicos ao mesmo tempo em que legitimou o tema na sociedade.

Uma verdade faz-se fundamental e foi convergente dentre os discursos: o SUS é um sistema de construção permanente da cidadania brasileira. Não houve divergência substancial sobre seus êxitos e avanços.

Todavia, foram explicitadas divergências sobre os desafios que ainda precisam ser enfrentados. Divergências essas que podem retroalimentar a complexidade que envolve o tema e estimular a adoção de ações para o monitoramento, controle e avaliação das ações e serviços de saúde.

Sobre as ideias centrais A ("O Direito à saúde deve ser garantido mediante políticas públicas") e B ("O Direito à saúde é garantia constitucional que independe de política pública"), merece destaque a intenção do STF, qualificado como representante máximo do Sistema Judiciário, em convocar a Audiência Pública. Disse especialmente do enfrentamento do senso comum, que dita apenas o argumento de que, nos processos judiciais de aplicação do direito à saúde, o Poder Judiciário pondera, de um lado, princípios orçamentários, separação de poderes (reserva do possível, lesão à ordem) e, de outro, o direito à vida.

O que ficou demonstrado é que há sempre um sopesamento de teses, que, por vezes, significa, inclusive para o Poder Judiciário, uma trágica escolha. Esses temas foram bem expostos nas ideias centrais C, D, E e F.

Caracterizada como uma questão controversa, não restou ao STF outra posição que não a adoção, como solução, da análise individual do caso concreto. $O$ Plenário do STF, seguindo o voto do relator, buscou solução de equilíbrio. Resumidamente, a decisão plenária do STF, nos recursos (STA) 175, 211 e 278; (SS) 3724, 2944, 2361, 3345 e 3355, e (SL) 47 asseverou que cada caso deverá ser observado conforme suas especificidades.

Quando o caso analisado referir-se a pedidos já contidos em políticas públicas existentes, o Poder Judiciário há que posicionar-se favoravelmente ao pleito. Todavia, 
quando o pleito referir-se a pedidos não contemplados pelas políticas públicas há que se observar: a) quando se tratarem de medicamentos sem registro na Anvisa, não há permissão legal para que a Administração Pública os adquira; b) quando se tratar de medicamentos sem evidência científica de sua eficácia ou adequação ao caso, outros pontos devem ser considerados: b.1) primeiramente se a política pública oferece tratamento àquela patologia - se sim, a oferta pública deve ser privilegiada; b.2) nos casos em que a oferta pública não se prestar ao usuário, que haja provas nos autos da ineficácia do tratamento oficial; b.3) nos casos de pedidos de tratamentos experimentais, esses devem ser custeados pelos interessados em sua avaliação, não havendo condenação ao sistema público de saúde; b.4) nos casos em que o tratamento pretendido não tenha sido incorporado pelo SUS e que não seja experimental, é preciso que o pedido esteja legitimamente acompanhado das provas da eficácia do pretendido, podendo até mesmo haver contestação do protocolo clínico (caso haja); c) nos casos em que não haja oferta pública, que o Poder Executivo apresente as justificativas ao caso e colabore com o Poder Judiciário na decisão de cada caso concreto, municiando-o com dados técnicos precisos.

Necessário então, observar a compatibilidade das ideias centrais identificadas e analisadas e os itens extraídos da decisão do STF.

Acerca da garantia do direito à saúde, aplicado ao caso concreto, a decisão do STF exarada nos processos identificados se posicionou em detrimento das ideias centrais $A$ e $B$ e em conformidade com o exposto na ideia $L$ ("O direito à saúde deve ser garantido mediante políticas públicas, todavia, admitidas excepcionalidades"). O conteúdo da ideia $L$ reconhece a necessidade ordeira da política pública, todavia, reconhece também sua falibilidade em determinados casos.

Quanto à solidariedade entre os entes, ainda que a ideia central dominante trate das competências específicas de cada ente (ideia central I: "A responsabilidade deve ser atribuída a cada ente federativo, conforme as competências definidas na lei"), o STF manteve a jurisprudência que se está consolidando e adotou a tese de que os entes são solidários na obrigação do direito à saúde, que foi exposto na ideia central H ("Há solidariedade entre os entes federativos para a garantia do direito à saúde"), defendida por menor percentual de atores presentes a audiência.

A ideia central $K$ trouxe conceitos bem entendidos pelo STF na aplicação do caso concreto, expressa no voto anteriormente comentado. Já o conteúdo da ideia central $\mathrm{M}$ não encontrou guarida nem foi mencionado pela Corte Suprema. 
Importa mencionar, ainda que não seja objeto de análise deste artigo, a edição da Recomendação no 31 do Conselho Nacional de Justiça (CNJ) que dispõe sobre as providências a serem tomadas pelos tribunais sobre da busca de informações e formação para os seus quadros de magistrados sobre Direito Sanitário e o funcionamento do SUS.

Para concluir, não há solução fácil para problema complexo e a judicialização do direito à saúde ainda padece de observação e análise, não mais de seu contexto teórico, mas de seu contexto prático e diuturno nos tribunais e na Administração Pública.

\section{Referências}

BARCELLOS, Ana Paula de. A eficácia jurídica dos princípios constitucionais: o princípio da dignidade da pessoa humana. Rio de Janeiro: Renovar, 2002. ISBN 85714780

BRASIL. Constituição (1988). [on line] Disponível em: http://www.planalto.gov.br/ccivil 03/Constituicao/Constituicao.htm (acesso em 23. jun 2013)

BRASIL. Decreto-Lei no 200, de 25 de fevereiro de 1967. Dispõe sobre a organização da Administração Federal, estabelece diretrizes para a Reforma Administrativa e dá outras providências. Diário Oficial da União, 27 de fevereiro de 1967. [on line] Disponível em: http://www.planalto.gov.br/ccivil 03/Decreto-Lei/Del0200.htm (acesso em 8 jul. 2014)

BRASIL. Lei no 6.360, de 23 de setembro de 1976. Dispõe sobre a Vigilância Sanitária a que ficam sujeitos os Medicamentos, as Drogas, os Insumos Farmacêuticos e Correlatos, Cosméticos, Saneantes e Outros Produtos, e dá outras Providências. [on line] Diário Oficial da União, 24 de setembro de 1976. Disponível em: http://www.planalto.gov.br/ccivil 03/Leis/L6360.htm (acesso em 8 jul. 2014)

BRASIL. Lei no 8.080, de 19 de setembro de 1990. Dispõe sobre as condições para a promoção, proteção e recuperação da saúde, a organização e o funcionamento dos serviços correspondentes e dá outras providências. (Lei Orgânica da Saúde). Diário Oficial da União, 20 de setembro de 1990 [on line] Disponível em: http://www.planalto.gov.br/ccivil 03/Leis/L8080.htm (acesso em 23 jun. 2014)

BRASIL. Lei o 8.689 , de 27 de julho de 1993. Dispõe sobre a extinção do Instituto Nacional de Assistência e Previdência Social (INAMPS) e dá outras providências. Diário Oficial da União, 28 de julho de 1993 [on line]. Disponível em: http://www.planalto.gov.br/ccivil 03/leis/L8689.htm (acesso em 14 jul. 2014)

BRASIL. Lei o 9.882 de 03 de dezembro de 1999. Dispõe sobre o processo e julgamento da arguição de descumprimento de preceito fundamental, nos termos do $\S$ 10 do art. 102 da Constituição Federal. Diário Oficial da União, 06 de dezembro de 1999 [on line]. Disponível em: http://www.planalto.gov.br/ccivil 03/leis/19882.htm (acesso em 14 jul. 2014) 
BRASIL. Ministério da Saúde. Portaria GM/MS no 3916, 30 de outubro de 1998. Aprova a Política Nacional de Medicamentos. Diário Oficial da União, 30 de outubro de $1998 . \quad$ [on line]. Disponível em http://bvsms.saude.gov.br/bvs/saudelegis/gm/1998/prt3916 $30 \quad 10$ 1998.html (acesso em 14 jul. 2014)

BRASIL. Ministério da Saúde. Portaria GM/MS no 2.475, 13 de outubro de 2006. Institui a RENAME. Diário Oficial da União, 18 de outubro de 2006 [on line]. Disponível em: http://www.diariodasleis.com.br/busca/exibelink.php?numlink=1-92-292006-10-13-2475 (acesso em 14 jul.2014)

BRASIL. Supremo Tribunal Federal (STF). Despacho de convocação de Audiência Pública, de 5 de março de 2009. [on line] Disponível em http://www.stf.jus.br/arquivo/cms/processoAudienciaPublicaSaude/anexo/Despacho

Convocatorio.pdf (acesso em 28 jul. 2010)

BRASIL. Supremo Tribunal Federal (STF). [voto Gilmar Mendes / Plenário do STF sobre os recursos: das Suspensões de Tutela (STA) 175, 211 e 278; das Suspensões de Segurança 3724, 2944, 2361, 3345 e 3355; e da Suspensão de Liminar (SL) 47. Em 17 de março de 2010. [on line] Disponível em http://www.stf.jus.br/arquivo/cms/noticiaNoticiaStf/anexo/STA175.pdf (acesso em 14 jul. 2014)

CARVALHO, Ernani. Em busca da judicialização da política no Brasil: apontamentos para uma nova abordagem. Revista de Sociologia Política. 23:115-126; 2004. ISSN 0104-4478

CONSELHO FEDERAL DE MEDICINA (Brasil) (CFM). Resolução ํo 1.931, de 17 de setembro de 2009. (Código de Ética Médica (2009/2010)). Diário Oficial da União, seção I, p. 173, de 13 de outubro de 2009. [on line] Disponível em: http://portal.cfm.org.br/index.php?option=com content\&view=category\&id=9\&ltemid=1 $\underline{22}$ (acesso em 8 jul. 2014)

CONSELHO NACIONAL DE SECRETÁRIOS DE SAÚDE (CONASS). Assistência Farmacêutica. Coleção Progestores, v. 7. Brasília: CONASS, 2007. ISBN 978-8589545-08-2

LEFÈVRE, Fernando e LEFÈVRE, Ana Maria Cavalcanti. O Discurso do Sujeito Coletivo. Um Novo Enfoque em Pesquisa Qualitativa (Desdobramentos). Caxias do Sul: EDUCS; 2003. ISBN 85-7061-246-X

MACHADO, Felipe R.S. e DAIN, Sulamis. A Audiência Pública da Saúde: questões para a judicialização e para a gestão de saúde no Brasil. Revista de Administração Pública, 46(4):1017-1036, jul-ago, 2012. ISSN 0034-7612. 